\section{The NCCN 2019 Annual Congress: Hematologic Malignancies}

\author{
Robert W. Carlson, MD
}

T The NCCN 2019 Annual Congress: Hematologic Malignancies provided an opportunity for more than 500 hematologists, hematologist/oncologists, and other healthcare professionals to see world-renowned experts in the management of hematologic malignancies present the latest treatment advances, updates to the standard of care as recommended in the NCCN Clinical Practice Guidelines in Oncology (NCCN Guidelines), and unique and challenging patient cases. This special issue of JNCCN_Journal of the National Comprehensive Cancer Network presents these Highlights as a synopsis of the proceedings.

This year's congress, co-chaired by Ranjana H. Advani, MD, Saul Rosenberg Professor of Lymphoma, Stanford Cancer Institute, and Andrew D. Zelenetz, MD, $\mathrm{PhD}$, Medical Director, Quality Informatics, Memorial Sloan Kettering Cancer Center, opened with a debate on chemoimmunotherapy as a first-line treatment for chronic lymphocytic leukemia and closed with a session on cytotoxic chemotherapy-free first-line therapy for follicular lymphoma. Between these sessions, a second debate evaluated the appropriate length of initial treatment of multiple myeloma. The congress also included 3 interactive sessions featuring patient case studies and panel discussions. In the first, moderated by Dr. Advani, panelists reviewed cases of lymphoma. In the second, Dr. Zelenetz directed a discussion on cases of rare and emerging subtypes of leukemia. And the final interactive session offered case studies and panel discussion on plasma cell neoplasms. Also in the congress, blood cancer experts described updates in treatment strategies for Hodgkin lymphoma, advances in first-line acute myeloid leukemia management, and progress in personalized therapeutic approaches in myelodysplastic syndromes. Specialists also presented on what clinicians need to know in the era of biosimilars, the evolution of therapy for relapsed/refractory multiple myeloma, diagnosis and management of Castleman disease, and management of recurrent acute lymphoblastic leukemia with T-cell engagement.

These Highlights of the NCCN 2019 Annual Congress: Hematologic Malignancies provide not only summaries of the latest updates in therapeutic strategies for both rare and common blood cancers, but also expert commentary and debate about any changes. This congress is just one of NCCN's educational events and programs, which include live meetings, webinars, and online learning opportunities. For more information about educational opportunities such as the NCCN 2020 Annual Congress: Hematologic Malignancies and the upcoming NCCN 2020 Annual Conference, and NCCN programs such as the seminal NCCN Guidelines, NCCN Compendia, and NCCN Global initiatives, and many more, visit NCCN.org.

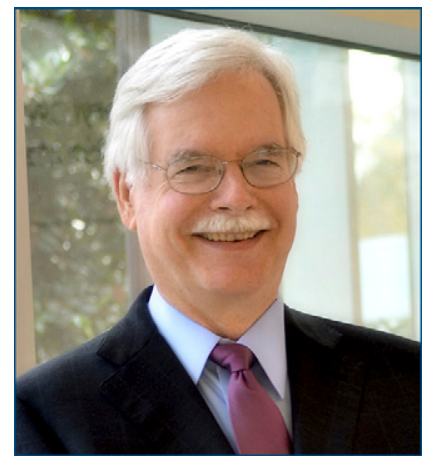

ROBERT W. CARLSON, MD

Robert W. Carlson, MD, joined NCCN as CEO in January 2013 following an esteemed history of leadership positions within the organization, including Representative to the NCCN Board of Directors, Chair of the Breast Cancer Guidelines Panel, and Member and Founding Chair of the Breast Cancer Risk Reduction Guidelines Panel. Prior to this appointment, he served as Professor of Medicine in the Division of Oncology and Stanford Medical Informatics at Stanford University Medical Center, as well as Medical Director of Inpatient Oncology and Hematology at Stanford Cancer Institute. Dr. Carlson is a graduate of Stanford University Medical School, and he completed his internship and junior residency in internal medicine at Barnes Hospital Group before returning to Stanford University to complete his senior residency. Dr. Carlson is board certified in Medical Oncology and Internal Medicine and is a member of several medical societies. He lectures extensively and has authored or co-authored more than 140 articles, abstracts, and book chapters. From 2001 through 2012, Dr. Carlson was selected by America's Top Doctors; from 1994 through 2011, he was selected by Best Doctors in America; in 2008, he was presented with the National Physician of the Year Award for Clinical Excellence by Castle Connolly Medical, Ltd.; and in 2010, Dr. Carlson was given the Founding Collaborator Award by the Breast Health Global Initiative (BHGl).

doi: $10.6004 /$ jnccn.2019.5025

The ideas and viewpoints expressed in this editorial are those of the author and do not necessarily represent any policy, position, or program of NCCN 